\title{
Identification of Bacteroides species from adult periodontal disease
}

\author{
B. I. DUERDEN, LINDA GOODWIN and T. C. A. O'NEIL*
}

\begin{abstract}
Departments of Medical Microbiology and "Restorative Dentistry, University of Sheffield Medical and Dental Schools, Beech Hill Road, Sheffield S10 2RX
\end{abstract}

\begin{abstract}
Summary. Samples from deep (4-7 $\mathrm{mm})$ periodontal pockets were collected from 17 patients with adult-type periodontal disease and one with the juvenile form of the disease. They were streaked immediately on selective and non-selective media and incubated anaerobically for $96 \mathrm{~h}$. There was a heavy growth of Bacteroides spp. from most samples and 10 representative colonies from each sample were sub-cultured for identification. In a total of 149 isolates from patients with adult-type disease, the commonest species were $B$. oralis (40), $B$. asaccharolyticus (35), B. intermedius (31), $B$. fragilis (12) and $\boldsymbol{B}$. ureolyticus (10); $\boldsymbol{B}$. gingivalis was not detected. The distribution of species was not distorted by multiple identical isolates from individual patients. There was a heavy growth of a single species, B. ureolyticus, from the patient with juvenile-type disease.
\end{abstract}

\section{Introduction}

Periodontal disease, a term that encompasses a range of inflammatory and destructive conditions of the tissues surrounding the teeth, is initiated by the overgrowth of bacteria in the gingival crevice (Socransky, 1977; Socransky et al., 1982) causing tissue damage by a combination of direct action of toxic bacterial products that include endotoxins (Hausmann et al., 1982) and hydrolytic enzymes such as collagenase and other proteolytic enzymes (Gibbons and MacDonald, 1961; Hardie, 1974), and stimulation of destructive host immunological responses (Genco, 1979). However, the role of particular bacterial species remains obscure, partly because of the complexity of the mixed microbial flora in the gingival crevice in health and disease (Moore et al., 1982; Socransky et al., 1982), and partly because there are several distinct forms of periodontal disease that affect patients in different age groups, progress in different ways, and probably have different microbial aetiologies (Schluger et al., 1977; Socransky et al., 1982).

The involvement of anaerobes has been clear since the early descriptions of the microflora of acute gingivitis by Plaut (1894) and Vincent (1896). Much interest has centred upon the roles of spirochaetes, fusobacteria and Bacteroides spp. of the melaninogenicus-oralis group. The spirochaetes

Received 21 Sep. 1986; accepted 3 Oct. 1986. are associated particularly with acute necrotising ulcerative gingivitis (Loesche, 1976; Loesche and Laughon, 1982) whereas the fusobacteria and bacteroides may be more important in other forms of periodontal disease. Bacteroides and fusobacteria are constant members of the normal microbial flora of the healthy gingival crevice (Slots, 1977) where the commonest species identified are members of the non-pigmented $B$. oralis complex, the pigmented $B$. melaninogenicus and $B$. intermedius, and Fusobacterium nucleatum (Duerden, 1980a). There have been several reports that the pigmented Bacteroides spp. are more common in periodontal disease (Slots, 1982) and improved identification methods have shown that various species of pigmented Bacteroides are found in different forms of the disease. $\boldsymbol{B}$. intermedius is commonly present in minimally inflamed advanced disease of long standing and in acute necrotising ulcerative gingivitis (Slots, 1982). B. gingivalis, an asaccharolytic species distinguished from $B$. asaccharolyticus in recent years (Coykendall et al., 1980; Kaczmarek and Coykendall, 1980), is found principally in advanced and inflamed severe periodontitis, with major tissue and alveolar bone destruction, and in generalised juvenile periodontal disease (Loesche et al., 1981). B. melaninogenicus, however, is common in people with healthy or diseased gingivae and has no specific association with periodontal disease (Slots, 1977 and 1982; Duerden, 1980a). The pigmented bacteroides secrete various toxic 
products that can cause tissue damage (Gibbons and MacDonald, 1961; Socransky, 1970; Mayrand et al., 1980). They also provoke potentially destructive host responses (Nisengard, 1977).

Anaerobes are not the only group of bacteria implicated in the pathogenesis of periodontal disease. Actinobacillus (Haemophilus) actinomycetemcomitans and Capnocytophaga ochracea may also play a part, especially in juvenile periodontal disease (Mandell and Socransky, 1981; Hammond and Stevens, 1982). However, the clinical and pathological features of the disease are characteristic of an anaerobe infection.

For the present investigation, methods developed in our laboratory for the isolation and identification of bacteroides and fusobacteria from the normal microbial flora of man and from clinical infections (Duerden, 1980 $a$ and $b$; Duerden $e t a l ., 1976$ and 1980; Rotimi et al., 1980) were used to examine the anaerobic bacterial flora of deep gingival pockets in patients with periodontal disease, principally of the adult type, attending the Charles Clifford Dental Hospital, Sheffield.

\section{Materials and methods}

\section{Patients}

Samples were collected from 17 patients with adulttype periodontal disease and from one 17-year-old patient with the juvenile form of disease. The bacteriological studies were done only at the patient's first visit to the Department of Restorative Dentistry, Charles Clifford Dental Hospital, and patients were not accepted if they had received specific treatment for their periodontal disease, including antibiotics, during the preceding month.

\section{Sampling}

Superficial plaque and debris were removed from the area considered clinically to be the most severely affected and material from a deep periodontal pocket $(4-7 \mathrm{~mm}$ in depth) was collected aseptically with a metal curette and seeded directly on to three plates of media for primary culture.

\section{Primary cultures}

The material from the periodontal pockets was plated immediately, in the clinic, on blood agar, BM agar (Williams et al., 1975) as used by Holbrook et al. (1978) and BM agar made selective for Bacteroides spp. by the incorporation of kanamycin $75 \mathrm{mg} / \mathrm{L}$ and vancomycin $2.5 \mathrm{mg} / \mathrm{L}$. All plates had been pre-reduced overnight in an anaerobic jar with an atmosphere of $\mathrm{H}_{2} 90 \%, \mathrm{CO}_{2} 10 \%$ at room temperature. The inoculum material was spread over a sector of the plate and streaked out in a standard manner to give a semi-quantitative assessment of growth as described by Rotimi and Duerden (1981). The inoculated plates were returned immediately to the Department of Medical Microbiology and placed in an anaerobic cabinet (Mark I Cabinet; Don Whitley Scientific, Shipley, W. Yorks) for incubation at $37^{\circ} \mathrm{C}$ in an atmosphere of $\mathrm{H}_{2} 10 \%, \mathrm{~N}_{2} 80 \%, \mathrm{CO}_{2} 10 \%$. They were inspected after $48 \mathrm{~h}$ and up to five representative colonies of gram-negative anaerobic bacilli were selected and subcultured on to fresh BM agar. The primary plates were re-incubated for a further $48-72 \mathrm{~h}$ and another five colonies were then selected to give a total of 10 from each subject. Examples of each colony type were selected and the number made up to 10 with colonies selected in approximate proportions to their comparative numbers on the primary isolation plates. The density of growth of each colony-type was recorded on a scale from + (isolated colonies in the inoculum well only) to +++ (many colonies extending into the second and third sets of streaks). The selected isolates were checked for purity on BM agar incubated anaerobically and on blood agar incubated aerobically and then suspended in a freezing medium of Nutrient Broth No. 2 (Oxoid) with inactivated horse serum (Wellcome) $10 \%$ and glucose $1 \%$ and held at $-70^{\circ} \mathrm{C}$ in a liquid nitrogen container until identification tests could be done.

\section{Identification of isolates}

The selected isolates were identified by a combined set of biochemical, tolerance, and antibiotic disk resistance tests (Duerden et al., 1976 and 1980; Rotimi et al., 1980) supported where appropriate by gas-liquid chromatography (GLC) of the fatty-acid end-products of metabolism. To distinguish between $B$. asaccharolyticus and $B$. gingivalis, all pigmented asaccharolytic strains were examined for: (i) fluorescence of colonies under ultraviolet illumination (Coykendall et al., 1980); (ii) agglutination of sheep erythrocytes (Slots and Genco, 1979); and (iii) production of phenylacetic acid, as determined by GLC analysis of non-volatile fatty-acid products (Kaczmarek and Coykendall, 1980).

\section{Results}

\section{Patients}

Of the 18 patients studied, 17 had adult-type periodontal disease; these had a mean age of 40 years (range 23-63 years) and there were 6 male and 11 female patients. The youngest of the 17, a 23-year-old male had rapidly destructive periodontal disease. The other patient was a 17-year-old male with the juvenile form of periodontal disease. 


\section{Primary cultures}

There was a heavy growth of gram-negative anaerobic bacilli from 16 samples, a light growth from one, and only four colonies were isolated from another. The latter specimen was heavily bloodstained and the atypical pattern of growth probably represented a problem of sampling. Of the 174 isolates selected for identification, four proved to be facultative $\mathrm{CO}_{2}$-dependent strains and 11 failed to grow on repeated subculture; 159 isolates from the 18 patients were subjected to the identification procedure.

\section{Identification of isolates}

The primary cultures of the sample from the patient with juvenile periodontal disease were clearly different from all the others. There was a heavy growth of gram-negative anaerobes, but all were the same species, $B$. ureolyticus. The isolates were characteristic of the species-fine gramnegative bacilli that were strictly anaerobic, sensitive to metronidazole, formed spreading colonies that produced pitting or corroding of the agar surface, did not produce acid from carbohydrates and were urease-positive.

The 10 identical isolates from the one patient were removed from further analysis. One hundred and forty-nine isolates from the other 17 patients were identified (table I). The commonest species were $B$. oralis (40), B. asaccharolyticus (35) and $B$. intermedius (31). $B$. fragilis and $B$. ureolyticus

Table I. Identities of 149 isolates of gram-negative anaerobic bacilli from 17 patients with adult-type periodontal disease

\begin{tabular}{lc}
\hline \multicolumn{1}{c}{ Species } & $\begin{array}{c}\text { Number of } \\
\text { isolates* }\end{array}$ \\
\hline Melaninogenicus-oralis group & \\
B. oralis & 40 \\
B. intermedius & 31 \\
B. melaninogenicus & 7 \\
B. bivius & 4 \\
B. disiens & 2 \\
Asaccharolytic group & \\
B. asaccharolyticus & 35 \\
B. ureolyticus & 10 \\
B. levi & 2 \\
Fragilis group & \\
B. fragilis & 12 \\
Fusiform group & \\
Leptotrichiabuccalis & 7 \\
\hline
\end{tabular}

* Up to 10 isolates were selected from each patient for identification; see Methods. provided 12 and 10 isolates respectively but there were only single-figure isolations of other members of the melaninogenicus-oralis group, and of Leptotrichia buccalis. Fusobacterium spp. were not detected, although two isolates from a repeat specimen from one of the patients were identified as $F$. nucleatum. Despite a detailed examination, none of the pigmented asaccharolytic strains proved to be B. gingivalis.

The distribution of species was not distorted by multiple identical isolates from only one or two patients. Several species were isolated from each patient and the order of frequency of the species remained more or less the same when the number of patients from whom each species was isolated were counted (table II). B. oralis was isolated from 11 patients, $B$. asaccharolyticus from nine, $B$. intermedius and $B$. ureolyticus from eight and $B$. fragilis from seven.

\section{Density of growth}

Most species gave a ++ or +++ growth on primary culture from about half the specimens from which they were isolated. The exceptions were $B$. fragilis, $\boldsymbol{B}$. intermedius and $\boldsymbol{B}$. oralis which, when present, usually provided a heavy growth (table II).

\section{Discussion}

With the exception of the one patient with juvenile periodontal disease and one with rapidly progressive disease, the patients examined in this

Table II. Frequency of isolation and density of growth of gram-negative anaerobic bacilli from 17 patients with adult-type periodontal disease

\begin{tabular}{lcc}
\hline & \multicolumn{1}{c}{$\begin{array}{c}\text { Number of patients } \\
\text { with given species }\end{array}$} \\
\cline { 2 - 3 } \multicolumn{1}{c}{ Species } & Total & Heavy growth \\
\hline Melaninogenicus-oralis group & & \\
$\quad$ B. oralis & 11 & 7 \\
$\quad$ B. intermedius & 8 & 6 \\
$\quad$ B. melaninogenicus & 4 & 1 \\
$\quad$ B. bivius & 3 & 0 \\
$\quad$ B. disiens & 1 & 0 \\
Asaccharolytic group & & \\
$\quad$ B. asaccharolyticus & 9 & 4 \\
$\quad$ B. ureolyticus & 8 & 5 \\
$\quad$ B. levi & 2 & 1 \\
Fragilis group & & \\
$\quad$ B. fragilis & 7 & 5 \\
Fusiform group & & \\
$\quad$ Leptotrichia buccalis & 5 & 3 \\
\hline
\end{tabular}


study were a clinically homogeneous group with adult-type periodontal disease. They were also bacteriologically similar. A heavy growth of gramnegative anaerobic bacilli was obtained from most patients and the general pattern of isolates was similar in all except the specimen from the patient with juvenile disease.

The species of Bacteroides isolated were a mixture of those usually present in the normal gingival flora (B. oralis, $B$. intermedius) and some that are not but are associated with necrotic and ulcerative lesions elsewhere in the body ( $B$. asaccharolyticus, $B$. ureolyticus, B. fragilis) (Finegold, 1977; Duerden, 1984). Most interest in periodontal disease has centred upon the role of pigmented species (Slots, 1982) and the contribution of $\boldsymbol{B}$. oralis is difficult to ascertain. Although a normal member of the gingival flora, it is not a harmless commensal at other sites in the head, neck and respiratory tract. It can be associated with soft-tissue abscesses of the head and neck, chronic otitis media and sinusitis, brain abscesses and lung abscesses (Finegold, 1977; Ingham et al., 1977; Duerden, 1984) and in these conditions it clearly has the capacity, particularly in mixed infections, for causing considerable tissue damage. However, recent studies have indicated that " $B$. oralis" represents a group of non-pigmented species with distinct properties (Shah et al., 1980; van Steenbergen et al., 1980) and further identification of the strains within this largest group of isolates may show specific associations with the disease state.

Identification of the pigmented isolates from our patients confirms that different species are associated with different groups of patients. $B$. intermedius, present only in small numbers in the normal gingival flora (Duerden, 1980a), was common in our patients. This distribution is similar to that described by Slots (1982). However, the species that has engendered most interest in recent years, $B$. gingivalis (Coykendall et al., 1980; Kaczmarek and Coykendall, 1980), was not detected. This is probably because it is principally associated with a different group of patients - those with generalised juvenile periodontal disease or with advanced, destructive periodontitis (Loesche et al., 1981). However, another pigmented member of the asaccharolytic groups of Bacteroides, B. asaccharolyti-

\section{REFERENCES}

Coykendall A L, Kaczmarek F S, Slots J 1980 Genetic heterogeneity in Bacteroides asaccharolyticus (Holdeman and Mcore 1970) Finegold and Barnes 1977 (approved list 1980 ) and proposal of Bacteroides gingivalis sp. nov. and cus, was the second most common species isolated from our patients. This species is recognised as a significant pathogen in necrotic ulcers and abscesses. It is the second commonest species of Bacteroides isolated from clinical specimens (Duerden, 1980b) and is associated particularly with perianal and perineal abscesses and ulcers and genital ulcers (Masfari et al., 1983), varicose and decubitus ulcers, and peripheral gangrene (Rissing et al., 1974). It has considerable destructive potential but since the differentiation of $B$. gingivalis its contribution to periodontal disease has not been considered important. Its role in adult-type disease requires further investigation.

A non-pigmented asaccharolytic species, $B$. ureolyticus, was also found in significant numbers, but less commonly than $B$. asaccharolyticus, in the patients with adult-type disease. The most remarkable finding was the heavy "pure" growth (in terms of Bacteroides spp.) of this organism from the patient with juvenile periodontal disease. As with $B$. asaccharolyticus, this species is associated with destructive, ulcerative conditions and abscesses elsewhere in the body, particularly perineal and genital ulcers (Duerden et al., 1982; Masfari et al., 1985); it has also been implicated as a cause of nonspecific urethritis (Fontaine et al., 1984). It would appear to have significant pathogenic capacity. Both $B$. asaccharolyticus and $B$. ureolyticus are strongly proteolytic and produce a range of enzymes capable of breaking down tissue components.

Although Bacteroides spp. are present in the gingival pockets in large numbers, the evidence for their pathogenicity remains circumstantial. They may be specific pathogens or merely indicators of a pathological process in the gingival crevice. The finding of species that are not part of the normal gingival flora and that have established pathogenicity at other sites supports the hypothesis that they are important in the pathogenesis of the disease. Further detailed, longitudinal studies, by quantitative methods, of the gingival flora in patients with periodontal disease are needed to answer these questions.

We thank the staff of the Restorative Dentistry Clinic for help with the patients and specimens and Mrs H. Storer for typing the manuscript.

Bacteroides macacae (Slots and Genco) comb. nov. International Journal of Systematic Bacteriology 30:559-564.

Duerden B I $1980 a$ The isolation and identification of Bacteroides spp. from the normal human gingival flora. Journal of Medical Microbiology 13:89-101.

Duerden B I $1980 b$ The identification of gram-negative anaerobic 
bacilli isolated from clinical infections. Journal of Hygiene 84:301-313.

Duerden B I 1984 Infections due to gram-negative non-sporing anaerobic bacilli. In: Wilson G R et al. (eds) Topley and Wilson's Principles of bacteriology, virology and immunity, vol. 3, 7th edn. Edward Arnold, London, pp. 311-326.

Duerden B I, Bennet K W, Faulkner J 1982 Isolation of Bacteroides ureolyticus (B. corrodens) from clinical infections. Journal of Clinical Pathology 35:309-312.

Duerden B I, Collee J G, Brown R, Deacon A G, Holbrook W P 1980 A scheme for the identification of clinical isolates of gram-negative anaerobic bacilli by conventional bacteriological tests. Journal of Medical Microbiology 13:231245.

Duerden B I, Holbrook W P, Collee J G, Watt B 1976 The characterization of clinically important gram-negative anaerobic bacilli by conventional bacteriological tests. Journal of Applied Bacteriology 40:163-188.

Finegold S M 1977 Anaerobic bacteria in human disease. Academic Press, New York.

Fontaine E A R, Borriello S P, Taylor-Robinson D, Davies H A 1984 Characteristics of a gram-negative anaerobe isolated from men with non-gonococcal urethritis. Journal of Medical Microbiology 17: 129-140.

Gibbons R J, MacDonald J B 1961 Degradation of collagenous substrates by Bacteroides melaninogenicus. Journal of Bacteriology 81 : 614-621.

Hammond B F, Stevens R H 1982 Capnocytophaga and Actinobacillus actinomycetemcomitans: occurrence and pathogenic potential in juvenile periodontitis. In: Genco $\mathbf{R} \mathbf{J}$, Mergenhagen S E (eds) Host-parasite interactions in periodontal diseases. American Society for Microbiology, Washington D.C., pp. 46-61.

Hardie J M 1974 Anaerobes in the mouth. In: Phillips I, Sussman $M$ (eds) Infection with non-sporing anaerobic bacteria. Churchill Livingstone, Edinburgh.

Hausmann E, Nair B C, Dziak R 1982 Bacterial components which result in bone loss. In: Genco $R \mathbf{J}$, Mergenhagen S E (eds) Host-parasite interactions in peridontal diseases. American Society for Microbiology, Washington D.C., pp. 151-159.

Holbrook W P, Ogston S A, Ross P W 1978 A method for the isolation of Bacteroides melaninogenicus from the human mouth. Journal of Medical Microbiology 11:203-207.

Ingham H R, Selkon J B, Roxby C M 1977 Bacteriological study of otogenic cerebral abscesses: chemotherapeutic role of metronidazole. British Medical Journal 2:991-993.

Kaczmarek FS, Coykendall A L 1980 Production of phenylacetic acid by strains of Bacteroides asaccharolyticus and Bacteroides gingivalis sp. nov. Journal of Clinical Microbiology 12: $288-290$.

Loesche W J 1976 Periodontal disease and the treponemes. In: Johnson R C (ed) The biology of parasitic spirochetes. Academic Press, New York, pp. 261-275.

Loesche W J, Laughon B E 1982 Role of spirochetes in periodontal disease. In : Genco R J, Mergenhagen S E (eds) Host-parasite interactions in periodontal diseases. American Society for Microbiology, Washington D.C., pp. 6275 .

Loesche W J, Syed S A, Morrison E C, Laughon B, Grossman N S 1981 Treatment of periodontal infections due to anaerobic bacteria with short-term treatment with metronidazole. Journal of Clinical Periodontology 8:29-44.

Mandell R L, Socransky S S 1981 A selective medium for Actinobacillus actinomycetemcomitans and the incidence of the organism in juvenile periodontitis. Journal of Periodontology 52:593-598.

Masfari A N, Kinghorn G R, Duerden B I 1983 Anaerobes in genitourinary infections in men. British Journal of Venereal Diseases 59 : 255-259.

Masfari A N, Kinghorn G R, Hafiz S, Barton I G, Duerden B I 1985 Anaerobic bacteria and Herpes simplex virus in genital ulceration. Genitourinary Medicine 61 : 109-113.

Mayrand D, McBride B C, Edwards T, Jensen S 1980 Characterization of Bacteroides asaccharolyticus and $B$. melaninogenicus oral isolates. Canadian Journal of Microbiology 26: 1178-1183.

Moore W E C, Ranney R R, Holdeman L V 1982 Subgingival microflora in periodontal disease: cultural studies. In: Genco R J, Mergenhagen S E (eds) Host-parasite interactions in periodontal diseases. American Society for Microbiology, Washington D.C., pp. 13-26.

Nisengard R J 1977 The role of immunology in periodontal disease. Journal of Periodontology 48:505-516.

Plaut H C 1894 Studien zur Bakteriellen Diagnostik der Diphtherie und der Anginen. Deutsche Medizinische Wochenschrift 20:920-923.

Rissing J P, Crowder J G, Dunfee T, White A 1974 Bacteroides bacteremia from decubitus ulcers. Southern Medical Journal 67:1179-1182.

Rotimi V O, Duerden B I 1981 The development of the bacterial flora in normal neonates. Journal of Medical Microbiology 14:51-62.

Rotimi V O, Faulkner J, Duerden B I 1980 Rapid method for the identification of clinical isolates of gram-negative anaerobic bacilli. Medical Laboratory Sciences 37:331-339.

Schluger S, Yuodelis R A, Page R C 1977 Periodontal disease: basic phenomena, clinical management and occlusal and restorative interrelationships. Lea and Febiger, Philadelphia.

Shah H N, Hardie J M, van Steenbergen T J M, de Graaf J 1980 Problems with the taxonomy of Bacteroides oralis. Journal of Dental Research 59D: 1823-1830.

Slots J 1977 Microflora in the healthy gingival sulcus in man. Scandinavian Journal of Dental Research $85: 247-254$.

Slots J 1982 Importance of black-pigmented Bacteroides in human periodontal disease. In: Genco R J, Mergenhagen $\mathrm{S} E$ (eds) Host-parasite interactions in periodontal diseases. American Society for Microbiology, Washington, D.C., pp. 27-45.

Slots J, Genco R J 1979 Direct hemagglutination technique for differentiating Bacteroides asaccharolyticus oral strains from non-oral strains. Journal of Clinical Microbiology 10:371373.

Socransky S S 1970 Relationship of bacteria to the etiology of periodontal disease. Journal of Dental Research 49:203-222.

Socransky S S 1977 Microbiology of periodontal diseasepresent status and future considerations. Journal of Periodontology 48: 497-504.

Socransky S S, Tanner A C R, Haffajee A D, Hillman J D, Goodson J M 1982 Present status of studies on the microbial etiology of periodontal disease. In: Genco R J, Mergenhagen S E (eds) Host-parasite interactions in periodontal diseases. American Society for Microbiology, Washington D.C., pp. 1-12.

van Steenbergen T J M, Shah H N, Hardie J M, de Graaf J 1980 Taxonomic studies on Bacteroides oralis. Antonie van Leeuwenhoek 46 : 231-242.

Vincent M H 1896 Sur l'étiologie et sur le lésions anatomopathologiques de la pourriture d'hôpital. Annales de l'Institut Pasteur 10: 488-510.

Williams R A D, Bowden G H, Hardie J M, Shah H N 1975 Biochemical properties of Bacteroides melaninogenicus subspecies. International Journal of Systematic Bacteriology 25: $298-300$. 